\title{
Stroke: Morbidity, Risk Factors, and Care in Taiwan
}

\author{
Fang-I Hsieh, Hung-Yi Chiou \\ School of Public Health, College of Public Health and Nutrition, Taipei Medical University, Taipei, Taiwan
}

Stroke is the third leading cause of death and the most common cause of complex disability in Taiwan. The annual age-standardized mortality rate of stroke is steadily decreasing between 2001 and 2012. The average years of potential life lost before age 70 for stroke is 13.8 years, ranked the fifth in the cause of death. Its national impact is predicted to be greater accompany aging population. The most common type of stroke was ischemic stroke in Taiwan. Small vessel occlusion was the majority of ischemic strokes subtype. Age, gender, hypertension, diabetes hyperlipidemia, obesity, atrial fibrillation, and smoking were important contributory factors to stroke morbidity. The standard treatment for acute ischemic stroke in Taiwan is providing the intravenous thrombolysis with recombinant tissue plasminogen activator (IV tPA) therapy for ischemic stroke patients within 3 hours of symptom onset. However, the rate of IV tPA therapy for patients with acute ischemic stroke is still low in Taiwan. Therefore, improving the public awareness of stroke warning signs and act on stroke and improving in-hospital critical pathway for thrombolysis would be the most important and urgent issues in Taiwan. To improve acute stroke care quality, a program of Breakthrough Series-Stroke activity was conducted from 2010 to 2011 and stroke centers were established in the medical centers. For the prevention of stroke, it was successful to increased annual smoke cessation rate through the 2009 Tobacco Hazards Prevention Act and decreased obesity rate through a nationwide weight-loss program conducted by Health Promotion Administration from 2011 to 2013 in Taiwan.

Keywords Stroke; Risk factors; Morbidity; Stroke care; Taiwan
Correspondence: Hung-Yi Chiou School of Public Health, College of Public Health and Nutrition, Taipei Medical University, No. 250 Wu-Hsing Street, Taipei 110, Taiwan

Tel: +886-2-23779188

Fax: +886-2-23779189

E-mail: hychiou@tmu.edu.tw

Received: May 2, 2014

Revised: May 19, 2014

Accepted: May 20, 2014

The authors have no financial conflicts of interest.

\section{Introduction}

Taiwan lies on the Tropic of Cancer, and its climate is marine tropical. The population in Taiwan is about 23.07 million people. Han Chinese made up the vast majority of people (98\%) and the remaining minority was composed of Austronesian indigenous groups. ${ }^{1}$ According to the Statistical Yearbook of Interior in $2012,{ }^{2}$ life expectancy of the total population at birth is 79.5 years ( 76.2 years in males and 83 years in females). The natural increase rate is $0.323 \%$. The proportion of persons aged 65 or over is approximately $11 \%$ and aging index is $76.2 \%$ great- er than the other Asia countries. All of the data shown that Taiwan's population is aging. The common health problems among older people are chronic diseases such as cardiovascular disease, stroke, and diabetes. The current health care system in Taiwan, known as National Health Insurance, was instituted on March 1st, 1995. The system provides equal access to health care for all inhabitants, and the population coverage had reached $99 \%$ by the end of 2004. ${ }^{3}$ A large computerized de-identified database, termed National Health Insurance research databases (NHIRD), was derived from this system by the Bureau of National Health Insurance, Taiwan (BNHI) and maintained by 
the National Health Research Institutes, Taiwan. The NHIRD containing registration and original claim data for reimbursement is provided to scientists in Taiwan for research purposes. In 2012, there were 502 hospitals and 20,935 clinics in Taiwan. The availability of hospital beds per 10,000 people and physicians per 10,000 persons in 2012 was approximately 69 beds and 20 physicians, respectively. There is about 1 physician for 500 people, on average.

Stroke is the third leading cause of death in Taiwan. It is also considered as the most common cause of complex disability. Post-stroke disability may leave survivors unable to work, which can lead to serious financial issues for survivors and their families. According to the data from the Ministry of Health and Welfare, ${ }^{4}$ the proportionate mortality of stroke is $7.2 \%$ in 2012. It is about 47 stroke deaths per minute. Using the 2000 WHO standard population, the annual age-standardized mortality rate of stroke is steadily decreasing from 57.8 to 30.8 per 100,000 between 2001 and 2012. Changes in stroke mortality rates are mainly attributable to the improvement of stroke survival, rather than incidence rates. There are 11,061 deaths from stroke (6,424 males and 4,635 females) in 2012. The average years of potential life lost before age 70 for stroke is 13.8 years, ranked the fifth in the cause of death. Stroke places a substantial burden on the national healthcare system, costing an estimated 475 million US dollars. Its national impact is predicted to be greater with aging population.

\section{Stroke types and subtypes}

Briefly speaking, stroke is caused by the interruption of blood supply to the brain or the rupture of blood vessels in the brain. Between 2006 and 2008, the Taiwan Stroke Registry, sponsored by the Ministry of Health and Welfare, engaged 39 academic and community hospitals to collect clinical data from 30,599 stroke admissions. ${ }^{5}$ As shown in Figure 1, this large scale stroke case surveillance program revealed that the most common type of stroke was ischemic stroke, accounting for almost $74 \%$ of all strokes. Other stroke types in order of frequency were intracerebral hemorrhage (ICH, 16.1\%), transient ischemic attack (TIA, 6.7\%), subarachnoid hemorrhage (SAH, $2.8 \%$ ), and cerebral venous thrombosis $(0.2 \%)$. According to the Trial of ORG 10172 in Acute Stroke Treatment (TOAST) criteria, ${ }^{6}$ the majority of ischemic strokes subtype in Taiwan was small vessel occlusion (37.7\%) followed by large artery atherosclerosis (27.7\%), cardioembolism (10.9\%), specific pathogenesis (1.5\%), and undetermined pathogenesis $(22.2 \%)$. Lee et al. ${ }^{7}$ reported that ischemic stroke subtypes among young patients ( 18 to 45 years old) were $20.5 \%$ of small-vessel occlusion, $7.2 \%$ of large-artery atherosclerosis, $17.8 \%$ of cardioembolism, $22.3 \%$ of specific pathogenesis, and $23.5 \%$ of undetermined pathogenesis.

\section{Stroke morbidity}

\section{Incidence}

A population-base study from Chen et al. ${ }^{8}$ reported that there were approximately 230 incidence cases of hospitalization daily attributable to stroke during the period from 1 January 2001 to 31 December 2007. Previously, the stroke incidence was estimated by several population-based studies. Hu et al. ${ }^{9}$ conducted a cohort study of 8,562 stroke-free people with 4-year follow up to observe new stroke occurrence. The average annual incidence rate of first-ever stroke for people aged 36 years or older in this study was 330 per 100,000 population. The other population-based stroke survey carried out in Kinmen between 1993 and 1996 reported that the average annual incidence rate of first-ever stroke for people aged 50 years or older was 527 per

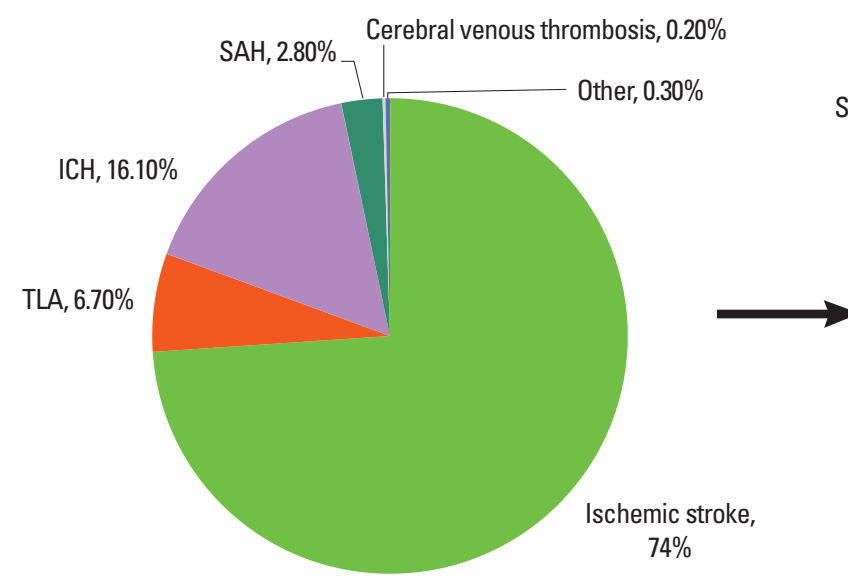

Subtype of ischemic stroke

Specific pathogenesis, $1.5 \%$

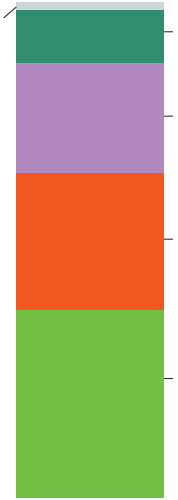

Cardioembolism, $10.9 \%$

Undetermined pathogenesis, $22.2 \%$

Large artery atherosclerosis, $27.7 \%$

Small vessel occlusion, $37.7 \%$

Figure 1. The type of stroke in Taiwan (the figure was created from the data of the Taiwan Stroke Registry ${ }^{5}$. 
Table 1. The studies of stroke morbidity in Taiwan

\begin{tabular}{|c|c|c|c|c|}
\hline Authors & $\begin{array}{l}\text { Study } \\
\text { period }\end{array}$ & Study area & Population & $\begin{array}{c}\text { Morbidity } \\
\text { per } \\
100,000\end{array}$ \\
\hline \multicolumn{5}{|l|}{ Incidence } \\
\hline Hu et al. ${ }^{9}$ & 1986-1990 & $\begin{array}{l}4 \text { urban and } \\
4 \text { rural communities }\end{array}$ & $\begin{array}{l}8,562 \text { adults } \\
\text { Age } \geq 36\end{array}$ & 330 \\
\hline Fuh et al. ${ }^{10}$ & 1993-1996 & Kinmen & $\begin{array}{l}3,081 \text { adults } \\
\text { Age } \geq 50\end{array}$ & 527 \\
\hline \multicolumn{5}{|l|}{ Prevalence } \\
\hline Hu et al." & 1986 & $\begin{array}{l}4 \text { urban and } \\
4 \text { rural communities }\end{array}$ & $\begin{array}{l}8,705 \text { adults } \\
\text { Age } \geq 36\end{array}$ & 1,642 \\
\hline Huang et al. ${ }^{12}$ & 1994 & 58 townships & $\begin{array}{l}4,972 \text { adults } \\
\text { Age } \geq 35\end{array}$ & 1,427 \\
\hline Lin et al. ${ }^{13}$ & 2001 & $\begin{array}{l}23 \text { administrative } \\
\text { districts }\end{array}$ & $\begin{array}{l}9,794 \text { adults } \\
\text { Age } \geq 35\end{array}$ & 1,930 \\
\hline
\end{tabular}

100,000 population. ${ }^{10}$ The studies of stroke incidence are summarized in Table 1.

\section{Prevalence}

$\mathrm{Hu}$ et al. ${ }^{11}$ reported the stroke prevalence for 8,705 people aged 36 or older was $16.42 / 1,000$ population $(95 \% \mathrm{CI}=13.89$ $19.42 / 1,000)$ in 1986 . The other studies estimated stroke prevalence of 14.27 per 1,000 in the people aged 35 or older using data from the 1994 National Health Interview Survey (NHIS) ${ }^{12}$ and 19.3 per 1,000 people from 2001 NHIS. ${ }^{13}$ In males, the stroke prevalence is 25.5 per 1,000 people, almost two-fold higher than the stroke prevalence in females (12.6 per 1,000 people). ${ }^{12}$ The level of urbanization, gender, heart disease, hypertension, and diabetes were important contributory factors to the stroke prevalence in Taiwan. ${ }^{12}$ The studies of stroke prevalence are summarized in Table 1.

\section{Risk factors}

\section{Nonmodifiable risk factors}

The unchangeable risk factors for stroke are age and gender. In a hospital-based study recruiting 1,085 stroke episodes in 1,021 patients between 2003 and 2005, the onset age was greater than 65 years in $66.6 \%$ of ischemic stroke patients. ${ }^{14}$ According to the Taiwan Stroke Registry, the medium age of patients at the onset of ischemic stroke/TIA, ICH, and SAH were 69.9 years, 62.2 years, and 57.6 years, respectively. ${ }^{5}$ Among ischemic stroke/TIA and ICH patients, the proportions of males were greater than females. However, in $\mathrm{SAH}$, the cases were more common in females.

\section{Modifiable risk factors}

The important changeable risk factors for stroke are hypertension, diabetes, hyperlipidemia, obesity, atrial fibrillation, and smoking.

\section{Hypertension}

Hypertension is a very common disease observed in the patients with ischemic stroke/TIA (79.2\%) or ICH (84.9\%). However, in the patients with $\mathrm{SAH}$, the prevalence of hypertension was only $65.3 \% .^{5}$ A prospective cohort study conducted by Lin et al. ${ }^{15}$ investigated the associations between adherence to Dietary Approaches to Stop Hypertension (DASH) foods or nutrients and blood pressure or stroke risk in 1,420 and 2,061 Taiwanese adults during 1989 to 2002, respectively. They found that adhering to the DASH diet was beneficial for long term blood pressure control and reduction of stroke risk (HR [hazard ratio], 0.63; 95\% CI, 0.41-0.98; $P=0.037$ ) in Taiwanese population. Another study using pregnant women as study cohort reported that women with hypertensive disorders in pregnancy had an increased risk of subsequent stroke (adjusted HR, 2.04; 95\% CI, 1.18-3.51). ${ }^{16}$ Among predictors for ischemic stroke in patients with atrial fibrillation, hypertension was the most powerful predictor except for prior TIA/stroke, and the magnitude of association (OR, 2.656; 95\% CI, 2.140-3.296) was greater than observed in white populations. ${ }^{17}$

\section{Diabetes}

The prevalence of type 2 diabetes has rapidly increased in the Taiwanese population, reaching $9.78 \%$ among adults aged 20 79 years in 2013. ${ }^{18}$ Increasing levels of obesity in the general population in the past two decades may be one of the principal factors contributing to the elevated incidence of type 2 diabetes. ${ }^{19}$ The prevalence of diabetes was $45.4 \%$ in ischemic stroke/ TIA and $37 \%$ in hemorrhage stroke. ${ }^{5}$ A Taiwanese populationbased study showed that diabetes were significantly associated with ischemic stroke in patients with atrial fibrillation (OR, 1.341 ; 95\% CI, 1.092-1.648). ${ }^{17}$ Cheng et al. ${ }^{20}$ randomly selected 14,856 patients with diabetes from the Taiwan National Health Research Institute database and followed up for 4 years to calculate their ischemic stroke incidence in two groups, one group used oral hypoglycemic agents metformin and the other without. The risk of ischemic stroke was substantially lower in the group with metformin use $(9.2 \%)$ than in the group without metformin use (17.5\%): adjusted HR (95\% CI) $=0.468$ (0.424$0.518)$.

\section{Hyperlipidemia}

Increasing body of evidence has demonstrated that hyperlipidemia is one of the well-defined and modifiable risk factors for ischemic stroke. The prevalence of dyslipidemia is about $49.4 \%$ in Taiwanese patients with ischemic stroke/TIA. ${ }^{5}$ Among young 
ischemic stroke patients aged 15-45 years, the prevalence of hyperlipidemia was $53.1 \%{ }^{7}$ It has been reported that every 1.0 $\mathrm{mmol} / \mathrm{L}$ reduction in low-density lipoprotein cholesterol is associated with a corresponding $21 \%$ reduction in stroke. ${ }^{21}$ Statins are medications used for the control of hypercholesterolemia. ${ }^{22}$ A nationwide population-based study using the Taiwan NHIRD reported that after the multivariate Cox regression model analysis adjusted for age, gender, comorbidities, and concomitant medication use, use of statins in hemodialysis patients was associated with a lower risk of developing future ischemic stroke (HR, 0.49; 95\% CI, 0.39-0.63) as compared to the hemodialysis patients without exposure to statins. ${ }^{23}$

\section{Obesity}

General obesity for Taiwanese was defined as BMI $\geq 27 \mathrm{~kg} / \mathrm{m}^{2}$, corresponding to a similar degree of fat composition to whites with a BMI of 30.8..$^{24}$ According to a nationwide population-based survey conducted in Taiwan, obesity prevalence $(\mathrm{BMI} \geq 27)$ in 2002 was $19.2 \%$ in men and $13.4 \%$ in women. ${ }^{25}$ Comparing the Taiwanese data with other countries, obesity prevalence was greater in Taiwan than in the other Asian countries, but less than in the western countries. ${ }^{26}$ Data from the Cardiovascular Diseases Risk Factor Two-Township Study showed that the prevalence of obesity in ischemic stroke patients was $25 \%$ in males and $35 \%$ in females. ${ }^{27}$ The authors also found that metabolic syndrome subjects with general obesity exhibited a greater risk of ischemic stroke.

\section{Atrial fibrillation}

A community-based prospective cohort study among 3,560 Taiwanese participants conducted by Chien et al. ${ }^{28}$ reported that atrial fibrillation prevalences were $1.4 \%$ in men and $0.7 \%$ in women. The authors also found that atrial fibrillation patients had nearly 4 times risk of stroke (age, gender-adjusted relative risk [RR], 3.87; 95\% CI, 2.12-7.15) compared with those without atrial fibrillation. Another study conducted by Chao et al. ${ }^{29}$ recruited 829 subjects with atrial fibrillation as study cohort and 8,290 study subjects without atrial fibrillation as control cohort. The control cohort was matched with study cohort by sex and age. The authors found that atrial fibrillation was a significant risk factor for ischemic stroke among females (HR, 7.77; 95\% CI, 3.97-15.19). The event rates for female patients with and without atrial fibrillation were $4.4 \%$ and $0.7 \%$, respectively. However, the event rates were similar between groups with and without atrial fibrillation for males. A possible interpretation for the gender difference in atrial fibrillation-related thromboembolism risk was that a higher von Willebrand factor level was observed in females with atrial fibrillation, but not in males with atrial fibrillation, as compared with that of non- atrial fibrillation patients. ${ }^{30}$ In a hospital-based study of 947 patients with first-ever ischemic stroke, the prevalence of atrial fibrillation was significantly higher in elderly patients aged 80 years or older (29\%) than in those aged less than 80 years (11\%). ${ }^{31}$

\section{Smoking}

According to the data from the Adult Smoking Behavior Surveillance System conducted by the Health Promotion Administration, Ministry of Health and Welfare in Taiwan, the smoking rate significantly dropped from $42.9 \%$ to $35 \%$ in males during 2004 to $2010 .{ }^{32}$ However, no marked difference in smoking rate was observed in females, which was $4.6 \%$ in 2004 and $4.1 \%$ in 2010. Data from a prospective hospital-based stroke registry showed that the prevalence of smoking in ischemic stroke patients was $57.7 \%$ in males and $6.8 \%$ in females..$^{33}$ In a nationwide survey of health and living status of 2,600 residents aged 65 years or older in Taiwan, heavy smoking ( $\geq 20$ cigarettes per day) was an independent risk factor for all stroke (OR, 1.71; 95\% CI, 1.04-2.80) and cerebral infarction (OR, 1.72; 95\% CI, 1.00-2.96). ${ }^{34}$ In a hospital-based stroke registry among 2,650 acute ischemic stroke patients in Taiwan, it was found that smoking correlated with greater severity of ischemic stroke on admission particularly for the stroke subtype of small-vessel occlusion. ${ }^{35}$ However, inverse association was observed between smoking and stroke severity of cardioembolism.

\section{Stroke care in Taiwan}

The standard treatment for acute ischemic stroke recommended by the Stroke Guidelines in Taiwan is providing the intravenous thrombolysis with recombinant tissue plasminogen activator (IV tPA) therapy for ischemic stroke patients within 3 hours of symptom onset. The major exclusion criteria for IV tPA therapy are age $>80$ years old, anticoagulant user, the initial NIHSS $>25$, and diabetes patients with prior history of stroke. According to the data from Taiwan Stroke Registry between 2006 and $2008,{ }^{5}$ only $8.84 \%$ of ischemic stroke patients who presented within 2 hours of symptom onset were given IV tPA treatment. Among patients with ischemic stroke or TIA, 94\% were treated with antithrombotics during hospitalization and $85 \%$ were on antithrombotics at discharge. The rates of anticoagulation used for atrial fibrillation and lipid-lowering drug used at discharge were $28.28 \%$ and $38.69 \%$, respectively, much less than the rates in the western countries. The discharge destination for majority of stroke cases were their homes, only a few of them went to nursing home. In order to improve acute stroke care quality, a Breakthrough Series-Stroke (BTS) activity was 
conducted by the Institute for Healthcare Improvement from August 2010 to July 2011 through a collaborative learning model focused on 14 performance indicators of stroke care among 24 hospitals in Taiwan. ${ }^{36}$ One year after BTS activity, it was successful to improve the achievement rate of most performance indicators of stroke care. Since 2001, stroke centers have been increasingly established in medical centers of Taiwan. Most stroke centers have a multidisciplinary team composed of neurology, neurosurgery, emergency department, neurological radiology, rehabilitation, nursing department, outpatient department, department of nutrition, and social welfare department to provide effective, timely care to stroke victims.

\section{Nationwide program for controlling risk factors}

Smoking is an important risk factor for stroke. The smoking rate among ischemic stroke patients was nearly $60 \%$ in males. Thus, smoking cessation should be an important initiative for stroke prevention. In January 2009, the Taiwan government amended the 1997 Tobacco Hazards Prevention Act by extending smoke-free areas to almost all enclosed work-places and public places, printing graphic health warnings on cigarette packages, totally banning tobacco advertisements, promotion and sponsorship and increasing tobacco taxes. The implementation of the 2009 Act was reported to be associated with the increased quit attempt rate and the increased annual cessation rate. ${ }^{37}$ The quit attempt rate raised significantly from $39.4 \%$ to $42.9 \%$ between 2007 and 2010. Furthermore, the annual cessation rate elevated significantly from $7.1 \%$ to $8.9 \%$. Obesity is the other important risk factor of stroke. The prevalence of obesity in ischemic stroke patients was about $25 \%$ in males and $35 \%$ in females. In order to decrease obesity rate, a nationwide weightloss program was conducted by Health Promotion Administration from 2011 to 2013 in Taiwan. A series of healthy-living campaigns were used to encourage people to exercise more and eat healthily. In this three-year program, more than a million Taiwanese lost $2.2 \mathrm{~m} \mathrm{~kg}{ }^{38}$

In summary, stroke was the third leading cause of death and the main cause of disability in Taiwan. Majority of stroke was ischemic stroke. Small vessel occlusion was the most common ischemic stroke subtype. The recommend treatment for acute ischemic stroke patients within 3 hours of symptom onset is IV tPA. However, the rate of IV tPA therapy in Taiwan was still far behind than the rate in the western countries. Therefore, in order to increase the tPA treatment rate, increasing the public awareness of stroke warning signs and act on stroke and improving inhospital critical pathway for thrombolysis would be the most important and urgent issues in Taiwan.

\section{References}

1. Taiwan in depth. http://taiwanindepth.tw/lp.asp?CtNode $=19$ 23\&CtUnit $=164 \&$ BaseDSD $=12 \& m p=10$. Accessed February $24,2014$.

2. Statistical yearbook of interior 2012. http://sowf.moi.gov.tw/ stat/year/list.htm. Accessed February 24, 2014.

3. Fanchiang C. Current issue: New IC health insurance card expected to offer many benefits. Taiwan Today. http://www.taiwantoday.tw $/$ ct.asp?xItem $=20439 \&$ CtNode $=122$. Accessed February 24, 2014.

4. Health statistics. Ministry of Health and Welfare. http://www. mohw.gov.tw/cht/DOS/Statistic.aspx?f_list_no=312. Accessed February 24, 2014.

5. Hsieh FI, Lien LM, Chen ST, Bai CH, Sun MC, Tseng HP, et al. Get With the Guidelines-Stroke performance indicators: surveillance of stroke care in the Taiwan Stroke Registry: Get With the Guidelines-Stroke in Taiwan. Circulation 2010;122: 1116-1123.

6. Adams HP Jr, Bendixen BH, Kappelle LJ, Biller J, Love BB, Gordon DL, et al. Classification of subtype of acute ischemic stroke. Definitions for use in a multicenter clinical trial. TOAST. Trial of Org 10172 in Acute Stroke Treatment. Stroke 1993;24: 35-41.

7. Lee TH, Hsu WC, Chen CJ, Chen ST. Etiologic study of young ischemic stroke in Taiwan. Stroke 2002;33:1950-1955.

8. Chen CC, Chen CS, Liu TC, Lin YT. Stock or stroke? Stock market movement and stroke incidence in Taiwan. Soc Sci Med 2012;75:1974-1980.

9. Hu HH, Sheng WY, Chu FL, Lan CF, Chiang BN. Incidence of stroke in Taiwan. Stroke 1992;23:1237-1241.

10. Fuh JL, Wang SJ, Liu HC, Shyu HY. Incidence of stroke on Kinmen, Taiwan. Neuroepidemiology 2000;19:258-264.

11. Hu HH, Chu FL, Chiang BN, Lan CF, Sheng WY, Lo YK, et al. Prevalence of stroke in Taiwan. Stroke 1989;20:858-863.

12. Huang ZS, Chiang TL, Lee TK. Stroke prevalence in Taiwan. Findings from the 1994 National Health Interview Survey. Stroke 1997;28:1579-1584.

13. Lin HC, Lin YJ, Liu TC, Chen CS, Chiu WT. Urbanization and stroke prevalence in Taiwan: analysis of a nationwide survey. J Urban Health 2007;84:604-614.

14. Lai SL, Weng HH, Lee M, Hsiao MC, Lin LJ, Huang WY. Risk factors and subtype analysis of acute ischemic stroke. Eur Neurol 2008;60:230-236.

15. Lin PH, Yeh WT, Svetkey LP, Chuang SY, Chang YC, Wang C, et al. Dietary intakes consistent with the DASH dietary pattern 
reduce blood pressure increase with age and risk for stroke in a Chinese population. Asia Pac J Clin Nutr 2013;22:482-491.

16. Wang IK, Chang SN, Liao CC, Liang CC, Chang CT, Lin HH, et al. Hypertensive disorders in pregnancy and preterm delivery and subsequent stroke in Asian women: a retrospective cohort study. Stroke 2011;42:716-721.

17. Lin LY, Lee CH, Yu CC, Tsai CT, Lai LP, Hwang JJ, et al. Risk factors and incidence of ischemic stroke in Taiwanese with nonvalvular atrial fibrillation-- a nation wide database analysis. Atherosclerosis 2011;217:292-295.

18. Diabetes in Taiwan 2013. International Diabetes Federation. http://www.idf.org/membership/wp/taiwan. Accessed March 2, 2014.

19. Chan JC, Malik V, Jia W, Kadowaki T, Yajnik CS, Yoon KH, et al. Diabetes in Asia: epidemiology, risk factors, and pathophysiology. JAMA 2009;301:2129-2140.

20. Cheng YY, Leu HB, Chen TJ, Chen CL, Kuo CH, Lee SD, et al. Metformin-inclusive therapy reduces the risk of stroke in patients with diabetes: a 4-year follow-up study. J Stroke Cerebrovasc Dis 2014;23:e99-e105.

21. Cholesterol Treatment Trialists' (CTT) Collaborators, Kearney PM, Blackwell L, Collins R, Keech A, Simes J, et al. Efficacy of cholesterol-lowering therapy in 18,686 people with diabetes in 14 randomised trials of statins: a meta-analysis. Lancet 2008;371:117-125.

22. Alberts AW. Discovery, biochemistry and biology of lovastatin. Am J Cardiol 1988;62:10J-15J.

23. Huang CC, Chan WL, Chen YC, Chen TJ, Chung CM, Huang $\mathrm{PH}$, et al. The beneficial effects of statins in patients undergoing hemodialysis. Int J Cardiol 2013;168:4155-4159.

24. Deurenberg P, Deurenberg-Yap M, Guricci S. Asians are different from Caucasians and from each other in their body mass index/body fat per cent relationship. Obes Rev 2002;3:141-146.

25. Yeh CJ, Chang HY, Pan WH. Time trend of obesity, the metabolic syndrome and related dietary pattern in Taiwan: from NAHSIT 1993-1996 to NAHSIT 2005-2008. Asia Pac J Clin Nutr 2011;20:292-300.

26. Global prevalence of adult obesity. http://www.worldobesity. org/site_media/uploads/Global_Prevalence_of_Adult_Obesity_January_2011.pdf. Accessed May 16, 2014.
27. Chen HJ, Bai CH, Yeh WT, Chiu HC, Pan WH. Influence of metabolic syndrome and general obesity on the risk of ischemic stroke. Stroke 2006;37:1060-1064.

28. Chien KL, Su TC, Hsu HC, Chang WT, Chen PC, Chen MF, et al. Atrial fibrillation prevalence, incidence and risk of stroke and all-cause death among Chinese. Int J Cardiol 2010;139:173180.

29. Chao TF, Liu CJ, Chen SJ, Wang KL, Lin YJ, Chang SL, et al. Atrial fibrillation and the risk of ischemic stroke: does it still matter in patients with a CHA2DS2-VASc score of 0 or 1 ? Stroke 2012;43:2551-2555.

30. Conway DS, Pearce LA, Chin BS, Hart RG, Lip GY. Prognostic value of plasma von Willebrand factor and soluble P-selectin as indices of endothelial damage and platelet activation in 994 patients with nonvalvular atrial fibrillation. Circulation 2003; 107:3141-3145.

31. Lee M, Huang WY, Weng HH, Lee JD, Lee TH. First-ever ischemic stroke in very old Asians: clinical features, stroke subtypes, risk factors and outcome. Eur Neurol 2007;58:44-48.

32. Adult smoking behavior surveillance system. http://tobacco. hpa.gov.tw/Show.aspx?MenuId=581. Accessed March 2, 2014.

33. Wu CY, Wu HM, Lee JD, Weng HH. Stroke risk factors and subtypes in different age groups: a hospital-based study. Neurol India 2010;58:863-868.

34. Lee TK, Huang ZS, Ng SK, Chan KW, Wang YS, Liu HW, et al. Impact of alcohol consumption and cigarette smoking on stroke among the elderly in Taiwan. Stroke 1995;26:790-794.

35. Weng WC, Huang WY, Chien YY, Wu CL, Su FC, Hsu HJ, et al. The impact of smoking on the severity of acute ischemic stroke. J Neurol Sci 2011;308:94-97.

36. Jeng JS. Quality improvement of acute ischemic stroke patients through the Breakthrough Series (BTS) activity. J Healthcare Qual 2012;6:70-75.

37. Chang FC, Sung HY, Zhu SH, Chiou ST. Impact of the 2009 Taiwan Tobacco Hazards Prevention Act on smoking cessation. Addiction 2014;109:140-146.

38. Taiwan wages nationwide battle with the bulge. BBC. http:// www.bbc.com/news/world-asia-21441916. Accessed May 16, 2014. 